\title{
DAS AMOREIRAS A SANTA TEREZA: VIEIRA DA SILVA E SUAS OBRAS $^{1}$
}

\author{
Luciene Lehmkuhl \\ Professora Adjunta do Instituto de H istória \\ Universidade Federal de U berlândia \\ lucilehmkuhl@ hotmail.com
}

\section{Resumo}

A vivência do casal Maria Helena Vieira da Silva e Arpad Szenes no Brasil (1940 a 1947) é apontada pela literatura como um interregno na produção plástica de cada um dos artistas, sendo com frequência, o período passado no país, referenciado como de grandes dificuldades de inserção no meio artístico. Este texto reflete acerca da produção plástica de Vieira da Silva, no seu "período brasileiro", apontando sobretudo as soluções por ela encontradas para dar continuidade à sua produção artística em meio às dificuldades do exílio. Estas soluções perpassam questões de ordem temática (referentes aos motivos pintados que se transformam consideravelmente), técnica (esboços em papel, guaches e desenhos em pequeno formato se proliferam) e pictórica (a cor, a luz, as linhas e a composição), e são percebidas na apreciação da obras.

Palavras-chave: arte; Portugal; Brasil.

Of the Amoreiras the Tereza Saint: Vieira da Silva and its Art

\begin{abstract}
The lifetime of the couple Maria Helena Vieira da Silva and Arpad Szenes in Brazil (from 1940 to 1947) is referenced by literature as an intervening period on the plastic production of each artist. It is also usually pointed as a period of difficulty about the insertion in the artistic enviroment. This text makes a reflection on Vieira da Silva's plastic production in her "brazilian period", indicating her solutions for the difficulties found in carrying on her artistic production during the exile. These solutions go beyond questions of thematic order (approaching painting issues that suffered considerable changes), technique order (sketches in paper, guache and drawings in small format increased) and pictorial order (the color, the light, the lines and the composition), and they are all noticed in the observation of the pieces.
\end{abstract}

Keywords: art; Portugal; Brazil. 
Pensava que comovíamos mais com a pintura figurativa, mas mesmo no figurativo as pessoas não viam como eu. Maria Helena Vieira da Silva

A pintora portuguesa Maria Helena Vieira da Silva transferiu-se no ano de 1940 para a cidade do Rio de Janeiro juntamente com seu marido, o também pintor Arpad Szenes. Ele apátrida por ser judeu húngaro, ela apátrida por ter com ele se casado e perdido, perante as leis portuguesas, o direito de cidadania. A vivência do casal no Brasil é reconhecida pela literatura como um interregno na produção plástica de cada um dos artistas, sendo com freqüência apontado o período passado no Brasil (1940 a 1947) como de grandes dificuldades de inserção no meio artístico, apesar das facilidades concedidas pelo governo brasileiro, como por exemplo, a emissão de passaportes diplomáticos.

Proponho refletir acerca da produção plástica de Vieira da Silva, no seu "período brasileiro", apontando, sobretudo, as soluções por ela encontradas para dar continuidade à sua produção artística em meio às dificuldades do exílio. Estas soluções perpassam questões de ordem temática (referentes aos motivos pintados que se transformam consideravelmente), técnica (seus esboços em papel, guaches e desenhos em pequeno formato se proliferam) e pictóricas (a cor, a luz, as linhas e a composição), podendo ser percebidas na apreciação da obras.

Nascida em Lisboa em 13 de Junho de 1908 e falecida em Paris, como cidadã francesa, em 6 de Março de 1992, Maria Helena Vieira conviveu desde cedo com diferentes pessoas de diversas culturas e países. Seu pai, o embaixador Marcos Vieira da Silva faleceu, vítima de tuberculose, quando ela estava com apenas três anos idade. A partir daquele momento a menina viveu com a mãe na casa do avô materno, republicano e diretor do jornal O Século, de Lisboa. Em Portugal, a República implantada em 1910, era ainda uma novidade com disputas travadas no campo político acentuando o clima de instabilidade econômica e social no país. Naquele período muitos portugueses deixaram Portugal com destino ao Brasil e, apesar de também se defrontarem com o regime republicano do outro lado do Atlântico, podiam contar com monarquistas convictos nas comunidades de imigrantes estabelecidos especialmente na cidade do Rio de Janeiro.

Em Lisboa, Maria Helena estudou pintura com professores particulares, mas também freqüentou, no ano de 1924, as aulas de Anatomia Artística da Escola de Belas Artes de Lisboa. Em 1928, então com 20 anos de idade, após uma viagem pela Itália decidiu mudar-se para Paris, acompanhada pela mãe. Freqüentou as aulas de escultura de Bourdelle, na Academia La Grande Chaumière e também as aulas de Despiau. Em seguida dedicou-se definitivamente à pintura, iniciando então seus estudos com Dufresne, Waroquier e Friez, época em que 
frequientou o atelier de Fernand Léger e participou de uma exposição no Salon de Paris $^{2}$. Naquela ocasião conheceu o pintor húngaro Arpad Szenes, com quem se casou em 1930. O casal viveu em Paris onde participou ativamente do meio artístico, sobretudo, da associação Amis du Monde, criada por artistas parisienses em resposta ao crescimento da extrema direita na Europa. No ano de 1933 a pintora realizou sua primeira exposição individual em Paris, organizada pela galerista Jeanne Bucher, onde foi também apresentado o livro infantil Kô et Kô, com ilustrações da artista.

Em junho de 1935 o poeta português António Pedro apresenta a primeira exposição da pintora em Portugal, o que a faz estar no país até outubro de 1936, quando aproveitou a oportunidade para restabelecer-se de uma grave doença que a acometeu. Só então regressou a Paris. Na ocasião, a referida exposição foi saudada também, como a primeira mostra de pintura abstrata que se fez no país desde o tempo de Amadeu de Souza-Cardoso, artista de vanguarda da geração futurista ${ }^{3}$.

\section{DA GUERRA E DAS COMEMORAÇÕES}

Talvez movidos pelas boas repercussões da exposição lisboeta, em tempos de guerra, o casal decidiu regressar a Portugal, afinal a situação em Paris tornara-se delicada para Arpad, em função de sua ascendência judia. Em Lisboa preparavam-se as comemorações dos Centenários de Portugal, artistas, operários e a população em geral viviam a efervescência dos preparativos para as festividades. Um discurso do Presidente do Conselho, Oliveira Salazar, publicado como Nota Oficiosa em 1938, apontava para a importância histórica das Comemorações, enfatizando que a Exposição do Mundo Português, principal atração do evento, deveria configurar-se como uma síntese da ação civilizadora de Portugal e da ação portuguesa na história do mundo. Salientava que a intenção de celebrar as datas comemorativas daria "ao povo português um tônico de alegria e confiança em si próprio, [além de] levar os serviços públicos e particulares a acelerar o ritmo da sua actividade, com o intuito de afirmar a capacidade realizadora de Portugal, os seus serviços à civilização" ". Nesta nota preliminar, de divulgação de intenções, aparecem enumeradas as finalidades das diversas etapas das Comemorações Centenárias. Em conjunto os atos, festejos e ações deveriam celebrar as datas históricas da nacionalidade (fundação 1140 e restauração 1640) e colocar em marcha novamente todo um potencial realizador, restituindo ao povo português e, conseqüentemente, à nação sua capacidade civilizadora, reafirmando a existência do Império Português.

O Estado Novo encontrou na celebração e no espetáculo proporcionados pela Exposição uma maneira eficaz de dar publicidade e de conseguir a adesão 
popular aos seus projetos de transformação da nação portuguesa. Esta deveria ser atualizada e modernizada, sua expressão deveria revestir-se dos valores simbólicos de um nacionalismo. Desta maneira, "o conceito de Nação esteve na raiz e origem de toda a teoria e prática política do período" estadonovista. Como demonstrou Jorge Ramos do Ó, em seu estudo, o Estado assumiu para si a definição dos caminhos da nação, já que aos sujeitos eram legadas as esferas da família, das freguesias, dos municípios e das corporações profissionais, deslocando-os da esfera da cidadania e retirando-lhes as possibilidades de influenciar na esfera da política ${ }^{6}$. Os dirigentes passam a utilizar a propaganda como instrumento de governo, lançando mão das "batalhas simbólicas" para "fazer coincidir a atividade governativa com uma atmosfera idealizada, de progresso e bem estar, [na qual] o campo cultural começará a ser reorganizado para materializar (...) uma doutrinação sistemática e tentacular sobre a sociedade civil" " .

A capacidade organizativa do Estado se fez notar naquele delicado momento no qual a Europa se encontrava a irrupção da Guerra que se iniciava, a qual não se podia prever a extensão, nem no tempo, nem no espaço. Ao optarem por dar continuidade ao processo comemorativo, restava vincular a instabilidade da situação bélica européia aos motivos e às finalidades das Comemorações e da Exposição. Assim, os discursos passaram a abordar a questão da Guerra, exaltando o exemplo português de unidade territorial, ordem e, sobretudo, paz. Augusto de Castro, o Comissário Geral da Exposição, defendia não apenas a manutenção das datas estabelecidas, mas também a oportunidade de aproveitar a vantagem criada pela circunstância da Guerra, que possibilitava um vasto alcance aos objetivos nacionais.

Numa Europa enfraquecida pelas lutas materiais não será inútil demonstrar uma supremacia do Espírito. Num mundo dividido pelas distensões da força e pelo paroxismo da violência não será descabido afirmar a existência e a confiança do Direito. Num momento em que as fronteiras caem como castelos de cartas, sob o vendaval das ambições e o mapa das nações se refaz a dinamite, a pacífica, unânime, demonstração da grande realidade de uma Pátria, imutável através dos séculos, representa a vitoriosa proclamação dum sólido Exemplo Nacional, que não pode ser indiferente ${ }^{8}$.

Estes mesmos motivos são explicitados no prefácio do Catálogo Oficial da Exposição, como uma lição de otimismo e fé em meio às 'nuvens da hora presente'. São, ainda, apontadas razões de ordem econômica para a manutenção das Comemorações na data prevista: os elevados custos para suspender ou destruir as obras já iniciadas; a impossibilidade de prever por quanto tempo as comemo- 
rações deveriam ser adiadas e, ainda, o fato de que a "significação nacional e simbólica das festas era incompatível com qualquer adiamento".

Quando da inauguração da Exposição do Mundo Português as primeiras páginas dos jornais portugueses eram divididas entre as notícias da Exposição e os acontecimentos da Guerra. Mesmo os periódicos vinculados ao Secretariado de Propaganda Nacional não excluíam as imagens da Guerra de suas primeiras páginas, ao contrário, elas pareciam reafirmar a possibilidade de leitura pretendida. A imagem de Portugal como nação soberana, que conseguiu atingir a paz em contraste com as outras nações européias, outrora fortes, industrializadas, modernas, civilizadas, mas, agora, em guerra. Esta era a deixa para a fala portuguesa, para a fala da cena principal, aquela que marcaria definitivamente a intenção dos festejos, a finalidade de todo o aparato propagandístico. A guerra como oposto da paz revelava a outra face das nações poderosas, aquilo que, encoberto pela grandiosidade dos Estados Nacionais, então se revelava ao mundo. A busca do poder pela subjugação do outro, a conquista territorial pelo deslocamento de populações eram evidentes nas manchetes dos jornais e acabavam por levar à descrença na civilidade pregada e propagandeada.

\section{DAS MONTRAS E DO ADEUS}

Quando Vieira da Silva e Arpad chegaram a Lisboa, em setembro de 1939, muitos artistas estavam sendo chamados a colaborar com os preparativos dos festejos centenários. Contavam-se com os artistas para criar a imagem plástica da história que se queria contar.

O Secretariado da Propaganda Nacional, na figura de seu dirigente António Ferro, propôs um concurso denominado Exposição de montras do Chiado, que pretendia ornamentar tantas vitrines quantas existissem na Rua Garrett, unindo o "espírito" e o "bom gosto" ${ }^{10}$. Deste concurso diversos artistas participaram entre eles Milly Possoz, Lino António, Maria Keil e Vieira da Silva que concorreu com as vitrines: Luva com Flores para a casa Luva Verde, Sapatos de sete léguas para a Sapataria Garrett e, ainda, Bailado de Tesouras para a Sheffield House, com a qual foi premiada. Na mesma época Vieira da Silva, pintou, por encomenda do Estado, um quadro com destino à Exposição do Mundo Português. No entanto, seu nome não aparece na lista dos cem artistas que trabalharam na Exposição arrolados no jornal para que o público pudesse distinguir "entre os pintores, escultores e arquitetos, os que melhor cumpriram dentro do plano do certame a sua missão estética" ${ }^{11}$.

Durante a estadia em Portugal Vieira da Silva e Arpad casaram-se em cerimônia religiosa na igreja de São Sebastião. Na mesma ocasião Arpad é batizado, convertendo-se ao cristianismo ${ }^{12}$. Permanecem em Lisboa morando na casa 
ao lado do Jardim das Amoreiras, período no qual a artista solicitou que lhe fosse devolvida a nacionalidade portuguesa, mas o governo não a concedeu. O casal decidiu, então, novamente partir. Desta vez para o Brasil, país no qual possuíam alguns amigos já imigrados e poderiam contar com certo apoio. Em junho de 1940, mesmo mês em que o Estado Novo inaugurava oficialmente a Exposição do Mundo Português, embarcaram "para o Rio de Janeiro, munidos apenas com passaportes de apátridas, expedidos pela Sociedade das Nações" ${ }^{13}$.

No Brasil as dificuldades de inserção artística e de adaptação pessoal ao clima e à cidade foram compensadas pela acolhida dos amigos e do próprio governo que lhes facultou passaportes diplomáticos e, posteriormente, uma proposta de naturalização, que não foi aceita. Mesmo assim, o casal permaneceu no país até 1947, quando então, regressou a Paris. Mesmo com inúmeras dificuldades, frequentemente apontadas na bibliografia que aborda a arte do período, ambos conseguem inserir-se no meio artístico brasileiro. Estabeleceram profunda relação de amizade com intelectuais e artistas, entre eles a poeta Cecília Meireles, o poeta Murilo Mendes e o pintor Carlos Scliar.

Os amigos brasileiros auxiliaram no estabelecimento de uma casa/atelier em Santa Tereza e na oportunidade de realizar exposições, trabalhos e ministrar aulas. Assim, nos anos de 1941 e 1946, Arpad expôs na Casa da Imprensa do Rio de Janeiro e na Sala dos Arquitetos, respectivamente. Vieira da Silva expôs no Museu Nacional de Belas Artes e na Galeria Askanasy, em 1942 e 1944. No ano de 1947 o casal, convidado por Jucelino Kubitsheck, expõe no Palácio Municipal de Belo Horizonte ${ }^{14}$.

\section{DO ABSTENCIONISMO E DO ABSTRACIONISMO}

A difusão da arte abstrata no Brasil está diretamente vinculada à presença de artistas estrangeiros no país, entre eles, Arpad e Vieira da Silva. Época de intensa discussão acerca dos rumos que tomariam as políticas culturais do Estado Novo brasileira (1937-1945). Intelectuais de diversos matizes engajaram-se aos projetos estadonovistas na tentativa de influenciar, de alguma maneira, na construção da nação. É de importância fundamental o papel assumido por órgãos como o Ministério de Educação e Saúde - MES e o Departamento de Imprensa e Propaganda - DIP, no âmbito da educação e da propaganda política, bem como, os postos assumidos pelos intelectuais nestes órgãos.

Naquele momento os ideais de brasilidade recaíam sobre a adequada fusão do originalmente brasileiro com o atualmente moderno. Buscava-se vincular o que de mais original, nativo e local existisse no solo pátrio com os maiores benefícios da modernização e do progresso. Dos intelectuais era esperado que descobrissem o veio de autenticidade da nação, por serem capazes de prenunciar os 
acontecimentos, conjugando a sensibilidade e a racionalidade inerentes aos 'intelectuais/profetas'. A partir desta noção o regime conseguiu vincular seus ideais, aos ideais modernistas de renovação nacional ${ }^{15}$.

Proliferava-se, no país, o debate acerca da pertinência em se abrir espaço para uma arte abstrata, entendida como universalizante e internacionalista. Intelectuais como Mário de Andrade saíram em defesa de uma arte nacional que conjugasse os interesses e as instituições da nova República e não os colocasse em risco. Nas palavras que proferiu na célebre Conferência de 1942, 'O movimento modernista', fez a crítica aos modernistas e clamou pelo não esquecimento da função social da arte:

Eu creio que os modernistas da Semana de Arte Moderna não devem servir de exemplo a ninguém. Mas podem servir de lição. O homem atravessa uma fase integralmente política da humanidade. Nunca jamais ele foi tão "momentâneo" como agora. Os abstencionismos e os valores eternos podem ficar para depois*. E apesar da nossa atualidade, da nossa nacionalidade, da nossa universalidade, uma coisa não ajudamos verdadeiramente, duma coisa não participamos: o amilhoramento político-social do homem. E esta é a essência mesma da nossa idade ${ }^{16}$.

Neste mesmo parágrafo o autor especifica em nota de pé-de-página a seguinte observação:

Sei que é impossível ao homem, nem ele deve abandonar os valores eternos, amor, amizade, Deus, a natureza. Quero exatamente dizer que numa idade humana como a que vivemos, cuidar desses valores apenas e se refugiar neles em livros de ficção e mesmo em técnica, é um abstencionismo desonesto e desonroso como qualquer outro. Uma covardia como qualquer outra. De resto, a forma pública da sociedade é um valor eterno também ${ }^{17}$.

Suas palavras estabelecem claramente o tom predominante à época da exposição de Vieira da Silva no Museu Nacional de Belas Artes. Desqualifica a 'técnica', a 'ficção' e a ascendência de 'valores eternos', definidos como "abstencionismo desonesto e desonroso", numa época de premência do social. Assim, as críticas aos trabalhos de Maria Helena não foram as mais favoráveis. O próprio Mário o define como "mero bordado" e Geraldo Ferraz, comentando a exposição da galeria Askanasy, como "mera aplicação decorativa que não merece ser comparada a uma epopéia" ${ }^{18}$.

Em meio tão hostil à sua produção plástica de teor vanguardista / abstracionista Vieira da Silva acaba por internalizar-se, juntamente com Arpad, no conví- 
vio conjugal e doméstico. As obras produzidas pelos dois artistas, neste período são indicativas do profundo convívio na intimidade do lar e do atelier. Arpad pinta Maria Helena e Maria Helena pinta Arpad. Ambos retratam-se juntos, abraçados, em casa, pintando, dormindo, lendo, desenhando. São cenas cotidianas, da esfera do privado e mais, da intimidade. Espaços interiores são mostrados, a vida íntima é publicizada na arte. Os próprios títulos das obras revelam: de Arpad, Le couple (1942), Dans l'atelier/ Rio (1945), Portrait de famille (1941), Marie Hélène X (1942), Bicho endormie (1940 -1947); de Vieira da Silva, Partie d'echecs (1942), L'interieur (1945), Autoportrait (1940 - 1947), L'harmonium et les échecs (1940), Portrait (1942). Tecnicamente, os dois fazem uso de variados suportes e materiais, sobretudo aqueles de fácil manuseio e acondicionamento, como os diversos tipos de papel e cartão, os lápis, a tinta da china, o guache, mas também o óleo sobre cartão ou sobre tela. Os formatos são predominantemente pequenos. Raros são os trabalhos que excedem um metro de altura ou largura.

Sobre a pintora no exílio, Claude Roy escreveu:

La pintura (en particular) y el arte (en general) no se pratican únicamente para poseer mejor lo que se posee (y los retratos de Arpad por Viera y de Viera por Arpad son eso, la felicidad de conocer mejor lo muy conocido, lo bien conocido...), sino también para recuperar lo que se há perdido, para reinventar lo que se nos escapa ${ }^{19}$.

Os temas da intimidade não são únicos, assim como não são homogêneas as soluções pictóricas e técnicas encontradas por Maria Helena no desenvolvimento do seu trabalho. Enquanto Arpad ministra aulas para jovens artistas brasileiros, Vieira da Silva explora o entorno urbano e retrata os amigos. Dedica-se a uma série de estudos e pinturas que abordam a paisagem e as edificações da cidade. La baie de Rio (1943), Corcovado (1940) e (1943), Silvestre (1943). Dedica-se também ao tema da guerra em obras como, Soldat tombe (c.1942), Les arbres en armes (1945), L'ange de la paix (1940-1947), História trágico marítima (1944). Esta última tomada como exemplo do vigor criativo e do esforço de trabalho mantidos pela artista, no Brasil. Esta obra, como emblema de seu potencial artístico contraria a crítica recorrente que imputa ao período brasileiro um momento de pausa na produção dos dois pintores, em especial de Vieira da Silva.

Neste viés, o período vivido no Brasil é visto como um interregno na produção plástica da artista acusada de ter abandonado a abstração por força do ambiente desfavorável encontrado no Brasil. No entanto, uma observação menos apressada e reducionista do conjunto de sua obra aponta para uma grande diver- 
sidade temática, técnica e de soluções plásticas. A crítica mais recente tem apontado este período como "de reflexão que veio dar riquíssimos frutos, mesmo ainda no Brasil" 20.

\section{DAS OBRAS, DO COTIDIANO E DA INTIMIDADE.}

Vejamos, portanto, a permanência de soluções plásticas, nas obras do período brasileiro, que muito se assemelham às soluções já encontradas nas obras abstratas produzidas no ambiente parisiense ${ }^{21}$. Em História trágico marítima (1944), a artista enlaça os personagens aflitos do naufrágio em torvelinhos de cores vibrantes, cujos contornos negros e ondulantes mal permitem decifrar as figuras por eles envolvidas. Vê-se miríades de formas que entrelaçam figuras humanas com figuras geométricas, estabelecendo uma solução pictórica cujo impacto visual se dá pelo conjunto confuso e denso advindo das linhas e cores, mais do que pelas expressões fisionômicas, ou posturas corporais das figuras retratadas.

Assim, também em Macumba (1946) os personagens dançantes são meros esquemas gráficos, traçados em negro sobre um fundo multi-colorido, que pigmenta losangos criando um vórtice de energia, diretamente ligado ao título da obra. Os mesmos losangos reaparecem em La rue des losanges (1947), esta totalmente entregue aos princípios da abstração. Nela não é possível identificar nenhum signo figurado que possa remeter a algo concretamente existente, visível e referente. Ainda em Les arbres en armes (1945), homens, árvores e armas se fundem e se confundem, chegando mesmo a se tornarem formas indefiníveis. As linhas negras se entrelaçam transformando homens em armas, armas em árvores e árvores em homens, deixando escapar as formas pré-estabelecidas que definam e diferenciam seres e objetos.

Mesmo nas obras explicitamente figurativas, Maria Helena demonstra seu inconformismo com a figuração. Seja na colagem sobre cartão La dame du coeur (1940), seja na têmpera também sobre cartão Interieur (1945). Em La dame... As letras aparecem como signos gráficos, que descontextualizados apenas emolduram a figura centralizada da dama a olhar seu cavaleiro. As letras são, neste caso, meros signos que já nada dizem. Em Interieur, composição marcada pela grande quantidade de linhas retas traçadas em variadas posições no espaço, chama atenção do espectador a figura que veste vermelho e joga xadrez. Não exatamente porque veste vermelho, afinal o próprio fundo no qual está localizada, também é vermelho. Além disso, as linhas que deveriam definir a figura acabam por se misturar às linhas do assoalho, levando o olhar do espectador ao jogo entre figura e fundo e não apenas à figura. Seu destaque, portanto, dá-se pela camuflagem, pelo mimetismo com o ambiente e não pela definição, pelo limite e fronteira 
entre os dois planos. Em toda a composição, é o único elemento a receber este tipo de tratamento plástico, no entanto, se o apagarmos do quadro, este perde a sua força compositiva tornando-se um simples interior.

Esta mesma solução aparece em diferentes obras de Vieira da Silva, algumas vezes por força da técnica utilizada, dos suportes e dos materiais com os quais planeja executar a versão definitiva das imagens esboçadas. Outras vezes por vontade deliberada de intervir no real como potência das imagens, como possibilidade da plástica e como campo escolhido de expressão. Enfrenta, portanto, veementemente a possibilidade de figurar, fazendo de suas composições um jogo de esconder e revelar formas, figuras, linhas e cores, as matérias primas daqueles que escolhem a plástica e a visualidade como meio de dizer o mundo.

Mesmo assim, a artista é acusada de conformar sua obra ao gosto predominante no Brasil, à representação do motivo em detrimento do tratamento formal. Ainda que discordando deste viés é preciso admitir que a abertura política e econômica que se empreendeu no Brasil com os desdobramentos do pós-guerra, com o fim do estado autoritário e com a redemocratização, levaram também a um maior interesse em fazer o país acertar o passo, na esfera artístico/cultural, com as outras nações. Os anos de 1950 marcaram, no Brasil, a busca desenfreada pela modernização e, assim como a arquitetura, a indústria automobilística e a urbanização, as artes plásticas ganharam espaço privilegiado como campo de realização do moderno. Logo, os museus, as galerias, os edifícios públicos e os interiores domésticos ficaram coalhados de obras abstratas, de renomados artistas estrangeiros e também nacionais.

Vieira da Silva passou então a ser lembrada por sua contemporaneidade, por sua capacidade de antever aquilo que posteriormente todos passariam a ver, mas, sobretudo, por se preocupar com a eficácia de suas obras perante o público ${ }^{22}$. Em 1961, recebeu o Prêmio Internacional de Pintura na Bienal de São Paulo.

Recebido em 08 de julho de 2008

\section{NOTAS}

${ }^{1}$ Este texto fo i reelaborado após ter sido apresentado com o título: Imagens do exílio: Vieira da Silva no Brasil no simpósio temático: Representaciones de la diaspora latinoamericana: trayectórias del exílio (literatura-arte-cine-historia) no V C ongresso Europeo de Latinoamericanistas - Bruxelas - abril 2007. ${ }^{2}$ LAM EG O , Valéria. D ois mil dias no deserto: Maria Helena no Rio de Janeiro, 1940-1947. In: VIEIRA DA SILVA N O BRASIL. São Paulo: MAM, 2007, p. 57. (catálogo da exposição).

${ }^{3}$ Cf. FRAN ÇA, José-augusto. A arte em Portugal no século XX (1911-1961). 3 ed. Lisboa: Bertrand, 1991, p.211. 
${ }^{4}$ Independência de Portugal (N ota O ficiosa da Presidência do Conselho). Revista dos Centenários. Lisboa, n.1, jan.1939, p.2

${ }^{5}$ Ó. José Ramos do. O s anos de Ferro - 0 dispositivo cultural durante a "Política do Espírito". Lisboa: Estampa, 1999, p.19.

${ }^{6}$ Idem, ibidem. p.21.

${ }^{7}$ Idem, ibidem, p.30.

${ }^{8}$ CASTRO, Augusto de. Ainda mais durante a Guerra! In: C ASTRO, A Exposição do M undo Português e a sua finalidade nacional. Lisboa: Empresa $\mathrm{N}$ acional de Publicidade, 1940. p.36.

${ }^{9}$ CASTRO, Augusto de. A Cidade da H istória. In: CASTRO, Ibidem, p.45.

${ }^{10}$ ACC IAIU O LI, M argarida. Exposições do Estado N ovo - 1934-1949. Lisboa: Livros H orizonte, 1998, p.152.

${ }^{11}$ C em artistas plásticos, numa notável parada de valores, trabalharam na Exposição do M undo Português. Diário de N otícias. Lisboa, 12 jul. 1940, p.4.

12 VIEIRA D A SILVA. Genève / Lisboa: Editions d'Art Albert Skira. 1993. p.404.

${ }^{13}$ RIBEIRO, José Sommer. Rever Arpad e Vieira da Silva. In: PIN ACOTECA DO ESTAD O DE SÃO PAU LO. Arpad Szenes - Vieira da Silva: Período brasileiro. São Paulo. 2001. Catálogo de Exposição. p.10.

${ }^{14} \mathrm{Cf}$. RIBEIRO, José Sommer. Ibidem, p.11.

${ }^{15} \mathrm{Cf}$. VELLO SO, M ônica Pimenta. O s intelectuais e a política cultural do Estado N ovo. In: DELGAD O, Lucília de Almeida N eves e FERREIRA, Jorge (org.) O Brasil Republicano - 0 tempo do nacionalestatismo: do início da década de 1930 ao apogeu do Estado N ovo. v.2. Rio de Janeiro: Civilização Brasileira, 2003, p. 170.

${ }^{16}$ AN DRADE, Mário de. 0 movimento modernista. Apud. AMARAL, Aracy A. Artes plásticas na Semana de 22. 5 ed. São Paulo: Ed. 34, 1998, p. 287.

17 Idem, ibidem, p. 287.

${ }^{18}$ Fragmentos destas críticas são citados por C O UTO, Maria de Fátima Morethy. Por uma vanguarda nacional. A crítica brasileira em busca de uma identidade artística (1940-1960). São Paulo: U nicamp, 2004 , p. 45. A autora também faz referência aos trabalhos de $\mathrm{N}$ elson Aguilar, nos quais o autor aborda as dificuldades encontradas pela artista e o tom desfavorável da crítica à sua obra. AGU ILAR, N elson. $\mathrm{N}$ otas de inverno sobre impressões de verão. In: Arpad Szenes e Vieira da Silva. Retratos. Rio de Janeiro: C hácara do Céu / São Paulo: Museu Lasar Segall. 1997. Catálogo da exposição. AGU ILAR, $\mathrm{N}$ elson. Figuration et spatialisation dans la peinture moderne brésilienne: le séjo ur de Vieira da Silva au Brésil. U niversité Jean Moulin - Lyon III. Lyon. 1984. Tese de doutorado.

${ }^{19}$ RO Y, Claude. Vieira da Silva. Barcelona: Ediciones Polígrafa. 1989, p. 18.

${ }^{20}$ RIBEIRO, José Sommer. O p.cit, p.14.

${ }^{21}$ As obras aqui indicadas podem ser vistas em publicações que registram exposições recentes da obra da pintora, ocorridas no Brasil. RIBEIRO, José So mmer. Rever Arpad e Vieira da Silva. In: PIN AC O TECA D O ESTAD O DE SÃO PAU LO . Arpad Szenes - Vieira da Silva: Perío do brasileiro. São Paulo. 2001. (catálogo da Exposição). VIEIRA DA SILVA N O BRASIL. São Paulo: MAM, 2007. (catálogo da exposição).

${ }^{22}$ BÉRAM, Diane Daval. 0 perío do brasileiro. In: VIEIRA DA SILVA. Lisboa/G enève: Editions d'art Albert Skia, 1993, p. 165. 